\title{
Determination of ascorbic acid using differential pulse voltammetry method on aniline-co-para-aminophenol modified electrode
}

\author{
Ali Parsa*, Maryam Tajik \\ Department of Chemistry, College of Science, Yadegar-e-Imam Khomeini (RAH) Shahre Rey Branch, Islamic Azad \\ University, Tehran, Iran \\ *corresponding author: e-mail: aliparsa@iausr.ac.ir,iausr.parsa@yahoo.com
}

\begin{abstract}
The electro-synthesis of poly(aniline-co-para-aminophenol) on graphite electrode was examined using cyclic voltammetry $(\mathrm{CV})$ over the potential window of $-0.2 \mathrm{~V}$ to $1 \mathrm{~V}$ in phosphoric acid medium, which was comprised of potassium chloride and para-Toluene sulfonic acid ( $p$ TSA) as electrolyte support. Fourier transform infrared (FTIR) spectroscopy was employed to identify the electro-synthesized copolymer while impedance techniques were used to determine charge transfer resistance (Rct) in modified and unmodified electrodes. After this, the electro-catalytic effect of the modified electrode on ascorbic acid was examined using differential pulse voltammetry (DPV) and a very strong response was observed. A negative shift of about $0.33 \mathrm{~V}$ was found in the peak anodic potentials for ascorbic acid. Measurement using DPV indicated a proper response by the electrode to a wide range of ascorbic acid concentrations, from 0.0001 to $0.0004 \mathrm{M}$. The peak anodic currents for increased concentrations showed a proper linear range.
\end{abstract}

Keywords: polyaniline, para-aminophenol, ascorbic acid, differential pulse voltammetry.

\section{INTRODUCTION}

Polyaniline is one of the oldest synthetic conductive polymers which has gained popularity for its high electrical conductivity ${ }^{\mathbf{1} 3}$. The presence of nitrogen atoms in phenyl rings results in the formation of different redox forms that affect the physical properties of polyaniline $e^{4,5}$. Polyaniline (PAni) can be obtained by chemical or electrochemical oxidative polymerization of aniline (Ani). Electro-polymerization is often carried out in an aqueous acidic medium through three techniques: galvanostatic, potentiostatic and cyclic voltammetry ${ }^{6,7}$. Electrochemical synthesis of PAni in aqueous solutions depends on different parameters such as the $\mathrm{pH}$ of electrolyte ${ }^{8}$, type of doping anion ${ }^{9}$, bed ${ }^{\mathbf{1 0}}$, and the techniques used for electrochemical synthesis ${ }^{11}$. Polyaniline exists in four main configuration states: (i) the fully-reduced leucoemeraldine (LE) form, (ii) the pernigraniline (PN) configuration that is fully-oxidized form, (iii) the half-oxidized emeraldine base (EB) form and the protonation of EB produces the emeraldine salt (ES) form, which contains a stable delocalized poly-semiquinone radical cation ${ }^{12,13}$. Electrodeposition of the PAni film at the surface of an electrode has been utilized extensively in a field of electrochemistry to modified electrodes for determination of some biological compounds based on electro-catalytic oxidation ${ }^{14,15}$. These catalytic activities of PAni are generally affected by a variety of solution conditions such as electrolytes, solvents and $\mathrm{pH}$ and also its intractable nature, such as insolubility and high brittleness, limits polyaniline's application. To extend its application in solutions, the copolymerization of Ani with ring-substituted Ani derivatives has been studied in order to modify the desired properties of polyanilines ${ }^{16,17}$. Recently, we synthesized copolymer of poly(aniline-co-ophenylenediamine), via the electrochemical copolymerization of Ani with ortho-phenylenediamine in aqueous solution ${ }^{15}$. The new copolymer had shown excellent electro-catalytic response towards the oxidation of ascorbic acid (AA). Ascorbic acid, commonly known as vitamin $\mathrm{C}$, improves absorption of amino acid and iron in the human body. It also con- nects tissues, bones, teeth, and the walls of blood vessel. Ascorbic acid is also an antioxidant agent. Therefore, it is essential to have a quick and selective method in the routine analysis of foods and drugs ${ }^{18,}{ }^{19}$. Many of the analytical methods used for determination of AA such as fluorimetry, chromatography, iodometric titration, enzymatic methods, spectroscopy and electrochemistry ${ }^{20-23}$. Due to high sensitivity, selectivity, precision, accuracy, wide linear range and low-cost instrumentation and time, electrochemical methods are currently of much interest for AA determination especially; differential pulse voltammetry (DPV) is a practical electrochemical analytical technique that offers quick response, low detection limit and simple use $\mathrm{e}^{24,25}$.

This study aims to investigate (i) the electro-synthesis of poly(aniline-co-para-aminophenol) on composite graphite electrode, (ii) electro-catalytic oxidation of AA and its measurement on modified electrodes using DPV method and (iii) the charge transfer resistance (Rct) of modified electrode on AA by electrochemical impedance spectroscopy (EIS).

\section{EXPERIMENTAL}

\section{Material}

Aniline (Ani) is distilled in a low-pressure nitrogen atmosphere. The resulting colourless liquid is stored at $5^{\circ} \mathrm{C}$. para-Aminophenol ( $\mathrm{AAP}$ ) was used without purification. Mineral salts like $\mathrm{KCl}$, para-Toluene sulfonic acid ( $p$ TSA), and $\mathrm{H}_{3} \mathrm{PO}_{4}$ were used without purification. All these substances were chemicals from Merck.

\section{Equipment}

CompactStat (manufactured by Ivium Technologies, the Netherlands) was used for the synthesis and identification of Ani-co-pAP copolymer. Electrochemical analyses were carried out in a handmade cell that had three common electrodes. Composite 2B pencil graphite $(1.8 \mathrm{~mm})$ was used as the working electrode while a platinum electrode 
was used as the auxiliary electrode, along with an $\mathrm{Ag} /$ $\mathrm{AgCl}$ reference electrode.

The structure of the copolymer was determined by fourier transform infrared (FTIR) spectroscopy system 2000 (TENSOR 27, Bruker).

\section{Procedure}

Electro-copolymerization of Ani and $p \mathrm{AP}$ was carried out using cycling voltammetry from $-0.2 \mathrm{~V}$ to $1 \mathrm{~V}$ in a solution comprised of $50 \mathrm{mM}$ of monomers and 10 $\mathrm{ml}$ of the supporting electrolytes $(\mathrm{KCl} 2 \mathrm{M}$ and $p$ TSA $0.6 \mathrm{M}$ ) in $\mathrm{H}_{3} \mathrm{PO}_{4}$ medium.

The inductive behaviour of copolymer of Ani with $p$ AP was identified in a three-compartment cell with a cell geometry that is similar to what has been described for the copolymerization at a potential of $0.05 \mathrm{~V}$, and a frequency range of $100 \mathrm{kHz}$ to $100 \mathrm{mHz}$ via electrochemical impedance spectroscopy (EIS).

The copolymer film formed on the working electrode was put on crystal $(\mathrm{KBr})$ for FTIR spectroscopy. Using Perkin Elmer 2000, a range of $400-2000 \mathrm{~cm}^{-1}$ was identified for the FTIR spectra.

DPV was used to measure ascorbic acid content, a modified electrode was selected and put into ascorbic acid solutions $(0.0001,0.0002,0.0003$, and $0.0004 \mathrm{M})$ and the resulting current vs. voltage was measured at the electroactive potential. CompactStat was again in this part of the analysis as well. The following parameters being employed: potential range of $-0.2 \mathrm{~V}$ to $1 \mathrm{~V}$; scan rate $0.1 \mathrm{~V} / \mathrm{s}$; pulse time $10 \mathrm{~ms}$; pulse amplitude $10 \mathrm{mV}$ and voltage step $10 \mathrm{mV}$.

\section{RESULTS AND DISCUSSION}

\section{Electro-synthesis and characterization}

\section{Electro-copolymerization of Ani and pAP}

Figure 1 depicts the voltammograms for the electro-copolymerization of Ani and $p \mathrm{AP}(0.05 \mathrm{M} p \mathrm{AP}+0.05$ $\mathrm{M}$ Ani) in phosphoric acid in the presence of a binary supporting electrolyte from $\mathrm{KCl}$ and $p$ TSA.

In Figure 1, the first voltammogram reveals two anodic peaks, one corresponding to the oxidation of $p \mathrm{AP}$ and the other corresponding to the oxidation of Ani. The

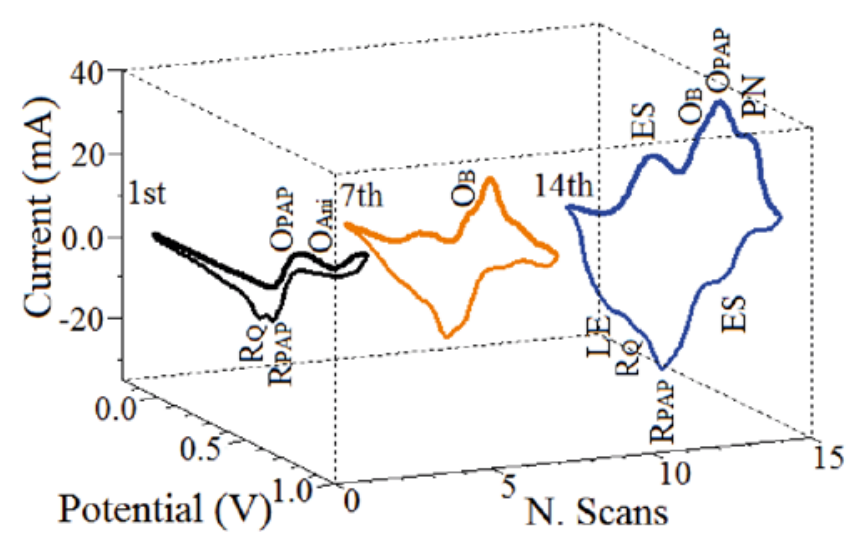

Figure 1. CVs $\left(1^{\text {st }}, 7^{\text {th }}\right.$ and $\left.14^{\text {th }}\right)$ of the electro-copolymerization of $50 \mathrm{mM}$ of monomers (Ani and $p \mathrm{AP}$ ) in phosphoric acid medium in the presence of binary supporting electrolyte $(\mathrm{KCl}$ and $p$ TSA). The scan rate is 100 $\mathrm{mVs}^{-1}$ anodic peak oxidation of Ani appears at $0.9 \mathrm{~V}$, which can be attributed to the synthesis of polyaniline due to formation of aniline radical cation ${ }^{26,27}$. On the reverse scan the cathodic peak is not observed. This is an irreversible electrode process. Two cathodic peaks are observed on the reverse scan indicate that reduction of $p \mathrm{AP}(\mathrm{R} p \mathrm{AP})$ and reduction of Quinoid $(\mathrm{Q})$ rings $(\mathrm{RQ})$ in copolymer chain that is attributed to the degradation of product (quinoid to benzenoid and vice versa), 12 . In the next scans ( Fig. 1: $7^{\text {th }}$ to $20^{\text {th }}$ ) redox pairs of PAni configuration and poly para-aminophenol (PpAP) appear in copolymer chain ${ }^{28}$. Given the redox pairs at the oxidation peaks (PN/ES/LE) of polyaniline configuration $^{29,30}$, it follows that the synthesis of polyaniline on the electrode occurs more slowly compared to the synthesis of PpAP.

\section{Structural analysis}

FTIR spectrum for electro-copolymerization of Ani and $p \mathrm{AP}$ in phosphoric acid medium in the presence of $\mathrm{KCl}$ and $p$ TSA is seen in Figure 2. FTIR spectrum resulting from copolymerization of Ani and $p \mathrm{AP}$ shows properties of both $p \mathrm{AP}$ and Ani hemopolymers. In Figure 2, the absorption bands $1646 \mathrm{~cm}^{-1}$ and $1555 \mathrm{~cm}^{-1}$ are associated with the quinoid and benzenoid vibration structures ${ }^{31}$ (intensities of quinoid and benzenoid bands are used to measure the level of oxidation in polyaniline films). A zero ratio indicates complete reduction, while a ratio ranging from 0.5 to 1 shows the presence of protoemeraldine. A ratio of 1 indicates relatively low oxidation and ratios greater than 1 imply complete oxidation. The absorption band at $1400 \mathrm{~cm}^{-1}$ is related to vibrational transitions ${ }^{32}$ in C-O-H and the one at $1305 \mathrm{~cm}^{-1}$ is related to the vibrational structure of the second aromatic amine that forms the C-N-C structure in the copolymer ${ }^{33}$. The band at $1114 \mathrm{~cm}^{-1}$ is associated with the modified planar $\mathrm{C}-\mathrm{H}$ bonds ${ }^{34}$. The bands at $1149 \mathrm{~cm}^{-1}$ and $805 \mathrm{~cm}^{-1}$ are related to the in-plane bending vibrations in $\mathrm{C}-\mathrm{H}$ bond and the out-of-plane bending vibration in aromatic rings respectively ${ }^{35}$. The presence of the band at $951 \mathrm{~cm}^{-1}$ can be attributed to the phosphate group ${ }^{36}$.

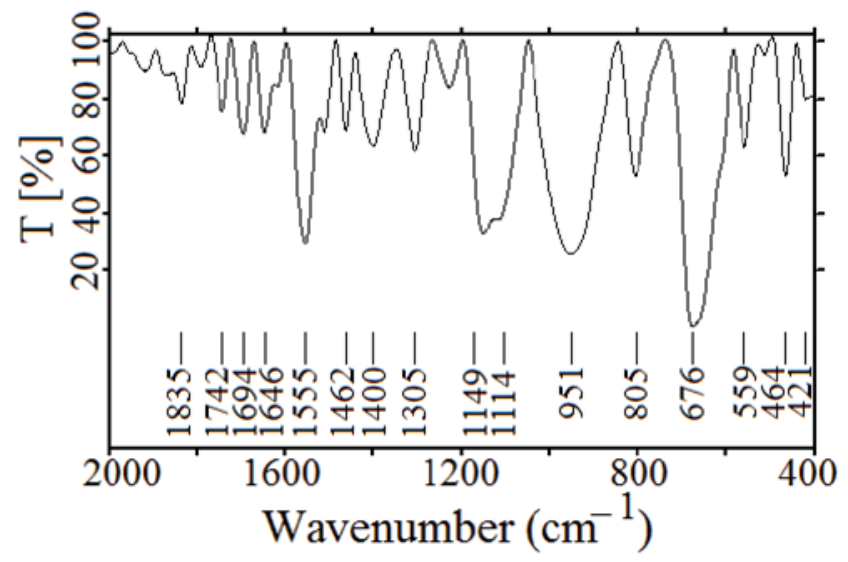

Figure 2. Baseline corrected FTIR spectra $\left(2000-400 \mathrm{~cm}^{-1}\right.$ region) of copolymer of Ani and $p \mathrm{AP}$ electrosynthesized in $1 \mathrm{M} \mathrm{H}_{3} \mathrm{PO}_{4}$ containing of binary supporting electrolyte 
Measurement of ascorbic acid (AA) using differential pulse voltammetry (DPV)

Figure 3a (black CVs) shows the DPV results for different AA concentrations (0.0001, 0.0002, 0.0003, and $0.0004 \mathrm{M}$ ) using graphite electrode. As seen in the figure, peak anodic potential of $0.38 \mathrm{~V}$ is observed on the graphite electrode. DVP results for different AA concentrations in phosphoric acid for the potential range of $-0.2 \mathrm{~V}$ to $1 \mathrm{~V}$ on the Ani-co-pAP modified electrode can be seen in Figure $3 b$ (blue CVs). As shown in the figure, the use of Ani-co-pAP modified electrode shifts anodic peaks to $0.05 \mathrm{~V}$ (a $0.33 \mathrm{~V}$ shift compared to the case where unmodified electrode is used). In addition, the peak anodic current is directly proportional to AA concentration and the measurement precision is in line with a correlation coefficient of 0.98 , which not only indicates the quick and easy oxidation of AA but also confirms the electro-catalytic effects of the Ani-co-pAP modified electrode on AA.

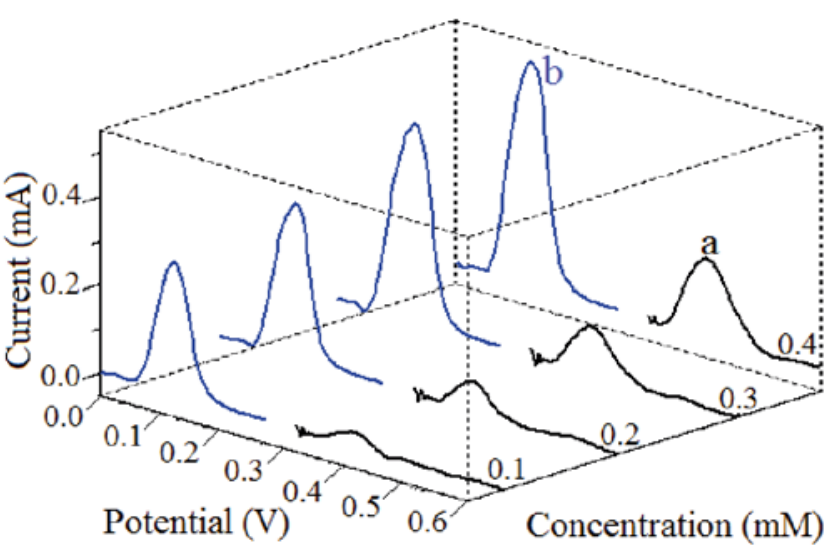

Figure 3. DPV voltammograms obtained from different concentrations (from 0.1 to $0.4 \mathrm{mM}$ ) of $\mathrm{AA}$ in $1 \mathrm{M}$ $\mathrm{H}_{3} \mathrm{PO}_{4}$ containing of binary supporting electrolyte (a) on bare graphite electrode and (b) on modified electrode

\section{Electrochemical impedance spectroscopy}

Figure 4 depicts the Nyquist plot obtained for Ani-co-pAP film in the phosphoric acid medium, which is comprised of supporting electrolytes of $\mathrm{KCl}$ and $p$ TSA.

The region used for impedance analysis largely falls within $0.05 \mathrm{~V}$ in both cathodic and anodic regions. Oxidation structures for Ani and $p \mathrm{AP}$ depend on the potential and $\mathrm{pH}$ of the electrolyte, and these two factors significantly affect the conductivity of the copolymer surface and the electrolyte ${ }^{37,38}$. Therefore, the impedance spectra of the Ani-co-pAP are expected to be influenced by DC potential. Impedance spectra of higher frequency were obtained for the electric double layer charge-discharge process. No electrochemical reaction occurs at lower potentials, leading to very high transfer resistance. This in turn may indicate a lack of electrical conductivity in Ani-co-pAP for the potential

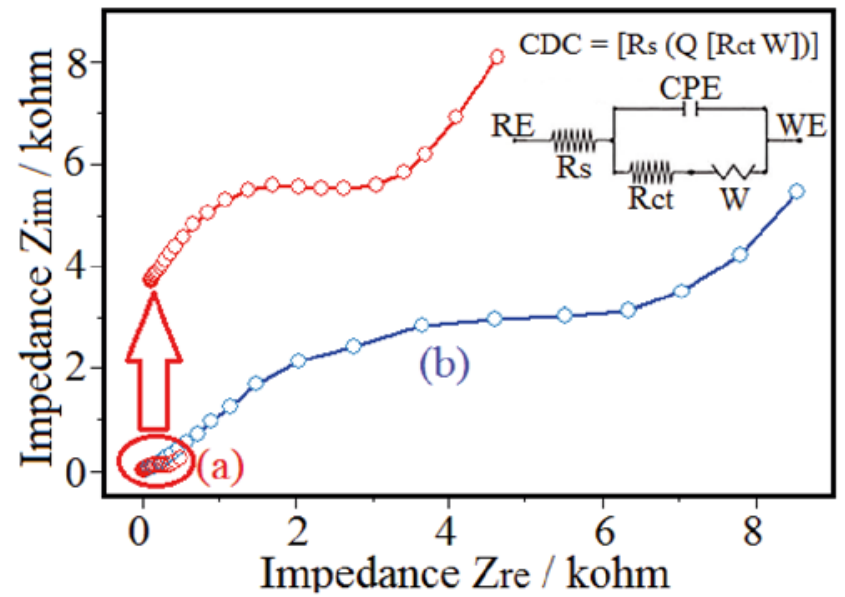

Figure 4. Nyquist plots of AA at the poly(Ani-co-pAP) modified electrode (a) and bare graphite electrodes (b) at applied potential of $0.05 \mathrm{~V}$ with Randle's equivalent circuit and circuit description code (CDC) (inset). The ac potential amplitude was kept at $10 \mathrm{mV}$ and frequency range used was from $100 \mathrm{kHz}$ to $100 \mathrm{mHz}$

range examined here. Once monomer oxidization begins at higher potentials, electron transfer takes place and therefore transfer resistance considerably falls ${ }^{39-42}$. As seen in Figure 4, spectra have a semi-circular shape indicating transfer resistance of the load. The smaller is the diameter of the semicircle, the easier it will be to transfer the electrons. However, reduced impedance at lower frequencies creates capacitive behaviour in the diffusion process. From Figure 4 it is obvious that the value of charge transfer resistance (Rct) of bare electrode (Fig. 4b) is much higher than poly(Ani-co- $p$ AP) modified electrode (Fig. 4a) indicating improved interfacial capacitance. The presence of straight line on modified and unmodified with a slope of $45^{\circ}$ at the lower frequency indicates a favourable diffusion-controlled mass transport process. Insert of Figure 4 presents the equivalent circuit for these impedance spectra ${ }^{43-45}$ with the following elements: the solution resistance of the bulk electrolyte (Rs), charge transfer resistance (Rct) that corresponds to the kinetic control of the process of electron transfer from solid phase (e.g. electrode) to liquid phase (e.g. solution) and vice versa, double layer capacitance $(\mathrm{Cdl})$ and Warburg impedance $(\mathrm{Zw})$. To get appropriate fitting of the Nyquist plots, Cdl is sometimes replaced by constant phase elements (CPE) in the Randles' equivalent circuit. The values of the Randles' equivalent circuit elements obtained by fitting the experimental results from the Nyquist plots at bare electrode and modified electrode at applied potential of $0.05 \mathrm{~V}$ are listed in Table 1.

Table 1. The best fitting values of the Randles' equivalent circuit elements in Figure 4 from the simulation of the impedance data for poly(Ani-co-pAP) modified electrode and unmodified electrode at applied potential of $0.05 \mathrm{~V}$

\begin{tabular}{|l|c|c|c|c|c|}
\hline \multirow{2}{*}{ Electrodes } & \multicolumn{5}{|c|}{ Randles' equivalent circuit elements } \\
\cline { 2 - 6 } & Rs $[\Omega]$ & Rct $[\Omega]$ & W $[1 /($ Ohm sqrt(Hz) $)]$ & CPE $(\mathrm{F})$ & $\mathrm{N}^{\mathrm{a}}$ \\
\hline Modified & 10 & $2.6 \times 10^{+2}$ & $1.9 \times 10^{+2}$ & $9.0 \times 10^{-6}$ & $8.1 \times 10^{-1}$ \\
\hline Unmodified & 69 & $6.9 \times 10^{+3}$ & $1.1 \times 10^{+3}$ & $1.9 \times 10^{-6}$ & $6.8 \times 10^{-1}$ \\
\hline
\end{tabular}

${ }^{a}$ Degree of electrode surface roughness or cell geometry. 


\section{CONCLUSION}

According to the electro-catalytic oxidation, the quantitative determination of ascorbic acid in the pharmaceutical, chemical, cosmetic and food industry was developed by the rapid, reliable, easy to implement, selective and sensitive DPV technique. The electroanalytical techniques advantages include excellent sensitivity, less sensitive toward the matrix effects, simultaneous determination of several analytes and there is no need the derivatization of the samples, extraction, filtration and complex sample preparation. In addition, the developed electroanalytical technique is less expensive than the other techniques.

The electro-copolymerization of Ani and $p \mathrm{AP}$ was carried out by cyclic voltammetry in a solution comprised of monomers and the supporting electrolytes $(\mathrm{KCl}$ and $p \mathrm{TSA}$ ) in $\mathrm{H}_{3} \mathrm{PO}_{4}$ medium. The poly(Ani-co-pAP) modified electrode exhibited electro-catalytic activity towards the oxidation reaction of AA with a higher current density and at lower onset potential. The extension of catalytic reaction depends on charge transfer. The electrochemical impedance spectroscopy was successfully used to interpret the electro-catalytic effect of modified and unmodified electrode on AA. The quantitative determination of ascorbic acid was developed by the quick, easy and sensitive DPV technique.

\section{ACKNOWLEDGEMENT}

The authors are indebted to the Yadegar-e-Imam Khomeini (RAH) Shahre-rey Branch, Islamic Azad University, Tehran, Iran for its financial support through the Research University (RU) grant (0823/1395/7637:95/05/19).

\section{LITERATURE CITED}

1. Luo, J., Zhang, H., Wang, X., Li, J. \& Wang, F. (2007). Stable Aqueous Dispersion of Conducting Polyaniline with High Electrical Conductivity. Macromolecules 40(23), 8132-8135. DOI: $10.1021 / \mathrm{ma} 070883 \mathrm{f}$.

2. Shirakawa, H., Louis, E.J., MacDiarmid, A.G., Chiang, C.K. \& Heeger, A.J. (1977). Synthesis of electrically conducting organic polymers: Halogen derivatives of polyacetylene, (CH)x. J. Chem. Soc. Chem. Commun. (16), 578-580. DOI: 10.1039/C39770000578.

3. Zhang, X., Wu, X., Yu, L., Yang, B. \& Zhou, J. (2015). Highly sensitive and selective polyaniline thin-film sensors for detecting SF6 decomposition products at room temperature. Synth. Met. 200(0), 74-79. DOI: 10.1016/j.synthmet.2014.12.033.

4. Niaura, G., Mazeikiene, R. \& Malinauskas, A. (2004). Structural changes in conducting form of polyaniline upon ring sulfonation as deduced by near infrared resonance Raman spectroscopy. Synth. Met. 145(2-3), 105-112. DOI: 10.1016/j. synthmet.2004.04.010.

5. Anilkumar, P. \& Jayakannan, M. (2007). Single-Molecular-System-Based Selective Micellar Templates for Polyaniline Nanomaterials: Control of Shape, Size, Solid State Ordering, and Expanded Chain to Coillike Conformation. Macromolecules 40(20), 7311-7319. DOI: 10.1021/ma071292s.

6. Gribkova, O.L., Nekrasov, A.A., Ivanov, V.F., Zolotorevsky, V.I. \& Vannikov, A.V. (2014). Templating effect of polymeric sulfonic acids on electropolymerization of aniline. Electrochim. Acta 122, 150-158. DOI: 10.1016/j.electacta.2013.12.025.

7. Gribkova, O.L., Omelchenko, O.D., Nekrasov, A.A., Ivanov, V.F. \& Vannikov, A.V. (2015). On the nature of influence of polyelectrolyte molecular weight on aniline electropolyme- rization. J. Solid State Electrochem. 19(9), 2643-2652. DOI: 10.1007/s10008-015-2853-4.

8. Chen, Z., Lv, H., Zhu, X., Li, D., Zhang, S., Chen, X. \& Song, Y. (2014). Electropolymerization of aniline onto anodic WO3 film: An approach to extend polyaniline electroactivity beyond pH 7. J. Phys. Chem. C. 118(47), 27449-27458. DOI: 10.1021/jp509268t.

9. Abalyaeva, V.V. \& Efimov, O.N. (2011). Synthesis and electrochemical behavior of polyaniline doped by electroactive anions. Russ. J. Electrochem. 47(11), 1299-1306. DOI: 10.1134/ S1023193511110024.

10. Han, J., Sohn, J., Cho, S., Jo, Y., Kim, J., Woo, H., Kim, H., Inamdar, A.I., Kim, H. \& Im, H. (2015). Synthesis of self-assembling carbon nanotube-polyaniline nanocomposite on a flexible graphene-coated substrate for electrochemical electrode applications. J. Korean Phys. Soc. 67(3), 512-517. DOI: $10.3938 / \mathrm{jkps} .67 .512$.

11. Heydari, M.H., Zebhi, H., Farhadi, K. \& Moghadam, P.N. (2016). Electrochemical synthesis of nanostructure poly(3-aminobenzoic acid), polyaniline and their bilayers on 430SS and their corrosion protection performances. Synth. Met. 220, 78-85. DOI: 10.1016/j.synthmet.2016.04.019.

12. Parsa, A. \& Ab Ghani, S. (2008). Electrocopolymerization of aniline and ortho-phenylenediamine via facile negative shift of polyaniline redox peaks. Polymer 49(17), 3702-3708. DOI: 10.1016/j.polymer.2008.06.044.

13. Parsa, A. \& Ab Ghani, S. (2009). Aqueous electrosyntheses of homo and copolymers of pyrrole and aniline in a binary electrolyte system. J. Electrochem. Soc. 156(6), E105-E111. DOI: $10.1149 / 1.3117345$.

14. Xie, A., Zhou, X., Zhou, W., Cai, K., Li, W., Luo, S. \& Yao, C. (2016). Fabrication of Pt/porous PANI using attapulgite as template for electro-oxidation of glycerol. Electrochim. Acta 189, 215-223. DOI: http://dx.doi.org/10.1016/j. electacta.2015.12.104.

15. Parsa, A. \& Amanzadeh-Salout, S. (2016). Electrocatalytic activity and electrochemical impedance spectroscopy of poly(aniline-co-ortho-phenylenediamine) modified electrode on ascorbic acid. Orient. J. Chem. 32(4), 2051-2058. DOI: $10.13005 / \mathrm{ojc} / 320432$.

16. Gizzie, E.A., Leblanc, G., Jennings, G.K. \& Cliffel, D.E. (2015). Electrochemical preparation of photosystem I-polyaniline composite films for biohybrid solar energy conversion. ACS Appl. Mater. Interfaces. 7(18), 9328-9335. DOI: 10.1021/ acsami.5b01065.

17. Liu, L., Cui, H., An, H., Zhai, J. \& Pan, Y. (2017). Electrochemical detection of aqueous nitrite based on poly(aniline-co-o-aminophenol)-modified glassy carbon electrode. Ionics 1-7. DOI: 10.1007/s11581-017-1972-6.

18. Zhang, L. \& Dong, S. (2004). The electrocatalytic oxidation of ascorbic acid on polyaniline film synthesized in the presence of camphorsulfonic acid. J. Electroanal. Chem. 568, 189-194. DOI: 10.1016/j.jelechem.2004.01.022.

19. Zuo, X., Zhang, H. \& Li, N. (2012). An electrochemical biosensor for determination of ascorbic acid by cobalt (II) phthalocyanine-multi-walled carbon nanotubes modified glassy carbon electrode. Sens. Actuat. B: Chemical 161(1), 1074-1079. DOI: 10.1016/j.snb.2011.12.013.

20. Dilgin, Y. \& Nişli, G. (2005). Fluorimetric determination of ascorbic acid in vitamin $\mathrm{C}$ tablets using methylene blue. Chem. Pharm. Bull. 53(10), 1251-1254. DOI: 10.1248/ cpb.53.1251.

21. Bagheri, H., Pajooheshpour, N., Jamali, B., Amidi, S., Hajian, A. \& Khoshsafar, H. (2017). A novel electrochemical platform for sensitive and simultaneous determination of dopamine, uric acid and ascorbic acid based on Fe3O4[sbnd] $\mathrm{SnO} 2$ [sbnd] Gr ternary nanocomposite. Microchem. J. 131, 120-129. DOI: 10.1016/j.microc.2016.12.006.

22. Solhjoo, A. \& Khajehsharifi, H. (2016). Multivariate calibration applied to the simultaneous spectrophotometric 
determination of ascorbic acid, tyrosine and epinephrine in pharmaceutical formulation and biological fluids. Curr. Anal. Chem. 12(6), 580-593. DOI: 10.2174/1573411012999160401 124820 .

23. Shekhovtsova, T.N., Muginova, S.V., Luchinina, J.A. \& Galimova, A.Z. (2006). Enzymatic methods in food analysis: determination of ascorbic acid. Anal. Chim. Acta 573-574, 125-132. DOI: 10.1016/j.aca.2006.05.015.

24. Ensafi, A.A., Taei, M., Khayamian, T. \& Arabzadeh, A. (2010). Highly selective determination of ascorbic acid, dopamine, and uric acid by differential pulse voltammetry using poly(sulfonazo III) modified glassy carbon electrode. Sens. Actuat. B: Chemical 147(1), 213-221. DOI: 10.1016/j. snb.2010.02.048.

25. Uzun, D., Balaban Gündüzalp, A. \& Hasdemir, E. (2015). Selective determination of dopamine in the presence of uric acid and ascorbic acid by N,N'-bis(indole-3-carboxaldimine)-1,2diaminocyclohexane thin film modified glassy carbon electrode by differential pulse voltammetry. J. Electroanal. Chem. 747, 68-76. DOI: 10.1016/j.jelechem.2015.03.036.

26. MacDiarmid, A.G. \& Epstein, A.J. (1989). Polyanilines: a novel class of conducting polymers. Farad. Discus. Chem.Soc. 88(0), 317-332. DOI: $10.1039 / \mathrm{dc} 9898800317$.

27. Zhang, L., Shi, Z., Lang, Q. \& Pan, J. (2010). Electrochemical synthesis of belt-like polyaniline network on p-phenylenediamine functionalized glassy carbon electrode and its use for the direct electrochemistry of horse heart cytochrome c. Electrochim. Acta 55(3), 641-647. DOI: 10.1016/j. electacta.2009.09.017.

28. Shimano, J.Y. \& MacDiarmid, A.G. (2001). Polyaniline, a dynamic block copolymer: Key to attaining its intrinsic conductivity? Synth. Met. 123(2), 251-262. DOI: 10.1016/ S0379-6779(01)00293-4.

29. Genies, E.M. \& Lapkowski, M. (1988). Polyaniline films. Electrochemical redox mechanisms. Synth. Met. 24(1-2), 61-68. DOI: 10.1016/0379-6779(88)90595-4.

30. Mu, S. (2004). Electrochemical copolymerization of aniline and o-aminophenol. Synth. Met. 143(3), 259-268. DOI: 10.1016/j.synthmet.2003.12.008.

31. Furukawa, Y. (1996). Electronic Absorption and Vibrational Spectroscopies of Conjugated Conducting Polymers. J. Phys. Chem. 100(39), 15644-15653. DOI: 10.1021/jp960608n.

32. Shah, A.u.H.A. \& Holze, R. (2006). Spectroelectrochemistry of aniline-o-aminophenol copolymers. Electrochim. Acta 52(3), 1374-1382. DOI: 10.1016/j.electacta.2006.07.040.

33. Liu, M., Ye, M., Yang, Q., Zhang, Y., Xie, Q. \& Yao, S. (2006). A new method for characterizing the growth and properties of polyaniline and poly(aniline-co-o-aminophenol) films with the combination of EQCM and in situ FTIR spectroelectrochemisty. Electrochim. Acta 52(1), 342-352. DOI: 10.1016/j.electacta.2006.05.013.

34. Brédas, J.L., Street, G.B., Thémans, B. \& André, J.M. (1985). Organic polymers based on aromatic rings (polyparaphenylene, polypyrrole, polythiophene): Evolution of the electronic properties as a function of the torsion angle between adjacent rings. J. Chem. Phys. 83(3), 1323-1329. DOI: 10.1063/1.449450.

35. Kosseoglou, D., Kokkinofta, R. \& Sazou, D. (2011). FTIR spectroscopic characterization of Nafion ${ }^{\circledR}$-polyaniline composite films employed for the corrosion control of stainless steel. J. Sol. State Electrochem. 15(11-12), 2619-2631. DOI: 10.1007/s10008-010-1241-3.

36. Liu, M., Krasteva, M. \& Barth, A. (2005). Interactions of phosphate groups of ATP and aspartyl phosphate with the sarcoplasmic reticulum Ca2+-ATPase: An FTIR study. Biophys. J. 89(6), 4352-4363. DOI: 10.1529/biophysj.105.061689.

37. Mondal, S.K., Prasad, K.R. \& Munichandraiah, N. (2005). Analysis of electrochemical impedance of polyaniline films prepared by galvanostatic, potentiostatic and potentiodynamic methods. Synth. Met. 148(3), 275-286. DOI: 10.1016/j. synthmet.2004.10.010.
38. Magdić Košiček, K., Kvastek, K. \& Horvat-Radošević, V. (2016). Hydrogen evolution on Pt and polyaniline modified Pt electrodes-a comparative electrochemical impedance spectroscopy study. J. Sol. State Electrochem. 20(11), 300-3013. DOI: 10.1007/s10008-016-3246-Z.

39. Chen, C., Sun, C. \& Gao, Y. (2008). Electrosynthesis of poly(aniline-co-p-aminophenol) having electrochemical properties in a wide $\mathrm{pH}$ range. Electrochim. Acta 53(7), 3021-3028. DOI: 10.1016/j.electacta.2007.11.039.

40. He, Z., Song, S., Ying, H., Xu, L. \& Chen, J. (2007). p-Aminophenol degradation by ozonation combined with sonolysis: Operating conditions influence and mechanism. Ultrason. Sonochem. 14(5), 568-574. DOI: 10.1016/j.ultsonch.2006.10.002.

41. $\mathrm{Mu}, \mathrm{S}$. (2006). Poly(aniline-co-o-aminophenol) nanostructured network: Electrochemical controllable synthesis and electrocatalysis. Electrochim. Acta 51(17), 3434-3440. DOI: 10.1016/j.electacta.2005.09.039.

42. Baldissera, A.F., Freitas, D.B. \& Ferreira, C.A. (2010). Electrochemical impedance spectroscopy investigation of chlorinated rubber-based coatings containing polyaniline as anticorrosion agent. Mater. Corros. 61(9), 790-801. DOI: 10.1002/maco.200905254.

43. Zic, M. (2007). The effect of the PANI-free volume on impedance response. J. Electroanal. Chem. 610(1), 57-66. DOI: 10.1016/j.jelechem.2007.07.001.

44. Moreira, F.T.C. \& Sales, M.G.F. (2017). Smart naturally plastic antibody based on poly $(\alpha$-cyclodextrin) polymer for $\beta$-amyloid-42 soluble oligomer detection. Sens Actuat. B: Chemical 240, 229-238. DOI: 10.1016/j.snb.2016.08.150.

45. Marmisollé, W.A., Inés Florit, M. \& Posadas, D. (2012). Electrochemically induced ageing of polyaniline. An electrochemical impedance spectroscopy study. J. Electroanal. Chem. 673, 65-71. DOI: 10.1016/j.jelechem.2012.03.016. 